\title{
STUDY OF CLINICAL PROFILE OF CHOLELITHIASIS IN KIMS, HUBLI
}

\author{
Byakodi K. G1, Vikram S2, Abhijit Hiregoudar³, Vishwas M. R², Vasant Teggimani', Narayan Kabade ${ }^{6}$
}

${ }_{1}^{1}$ Associate Professor, Department of Surgery, KIMS, Hubli, Karnataka, India.

${ }^{2}$ Specialist Surgeon, Department of Surgery, KIMS, Hubli, Karnataka, India.

${ }^{3}$ Associate Professor, Department of Surgery, KIMS, Hubli, Karnataka, India.

${ }^{4}$ Postgraduate Student, Department of Surgery, KIMS, Hubli, Karnataka, India.

${ }^{5}$ Senior Resident, Department of Surgery, KIMS, Hubli, Karnataka, India.

${ }^{6}$ Assistant Professor, Department of Surgery, KIMS, Hubli, Karnataka, India.

\section{BACKGROUND}

ABSTRACT

Gallstone disease is one of the most common problems affecting the digestive tract. The clinical spectrum of cholelithiasis ranges from an asymptomatic state to fatal complications. The prevalence of gallstones appears to be rising and each year approximately one million new cases are discovered. In India it is estimated to be around 4\%, whereas in the western world it is about $10 \%$. It is possibly due to change in dietary habits and lifestyle modifications. Studies on gallstone composition carried out in different parts of the world indicate a close link with dietary habits and ethnicity.

\section{MATERIALS AND METHODS}

This is a descriptive study conducted in Department of Surgery, KIMS, Hubli from April 2014 to Nov 2015. Totally 56 patients diagnosed to have symptomatic cholelithiasis with or without choledocholithiasis on Ultrasonography, who underwent surgery were studied. Initially all cases were examined, investigated, detailed history was taken and operated during the period. All patients have undergone detailed investigations; relevant investigations like Bile Culture and Cytology and Biochemical Analysis of Gallstones.

\section{RESULTS}

The highest incidence of cholelithiasis was in the 5th and 6th decade with maximum incidence in the 6th decade. There was an increased incidence in females, i.e. $\mathrm{M}$ : $\mathrm{F}=1$ : 27 . Pain was the most common symptom present in $94.64 \%$ of the patients, nausea and vomiting were the second most common symptoms presenting in $26.78 \%$ of patients and jaundice in $7.14 \%$ of the patients. Tenderness in the right hypochondrium was the most common sign present in $66.07 \%$ and guarding in $5.35 \%$ of the patients. $75 \%$ patients had mixed diet and $25 \%$ patients were vegetarian. Ultrasonography was the investigation of choice in our hospital. $78.57 \%$ patients had gallstones, $7.14 \%$ of patients had CBD stone, $17.85 \%$ of patients had single stone, $60.71 \%$ of patients had multiple stones, $19.64 \%$ of patients had thickening of gallbladder, $14.28 \%$ had dilated CBD, $21.42 \%$ had contracted GB and $25.00 \%$ patients had associated findings. 53.58\% of patients underwent laparoscopic cholecystectomy, $14.28 \%$ of patients underwent open cholecystectomy and associated procedure with cholecystectomy done in $17.86 \%$ of patients. Wound infection was the most common post-operative complication occurring in $12.50 \%$ patients and $5.35 \%$ patients had post-operative bile leak. Histopathology revealed $69.63 \%$ patients had chronic cholecystitis, $10.70 \%$ patients had calculous cholecystitis and $3.57 \%$ had acute cholecystitis with cholelithiasis. Bile culture revealed no growth in $39.28 \%$ patients. Gallstones analysis showed pigmented stone in $47.36 \%$ of the cases as the most common variety, mixed stones in $42.10 \%$ of cases followed by cholesterol stones in $10.52 \%$ of the cases. There was no mortality in the present study.

\section{CONCLUSION}

Gallstones disease is more common in female sex. The incidence of gallstones was higher in the 5th and 6th decades of life. Gall stones incidence is more in non-vegetarians than vegetarians. Upper abdominal ultrasonography was the investigation of choice and helps in early screening and detection of gallstones. It showed multiple gallstones and thickening with contraction of the gallbladder in the majority of cases. The commonest type of the stone was pigment stone. Laparoscopic cholecystectomy is better than any other procedure for cholecystectomy. Early cholecystectomy is the treatment of choice in symptomatic patients. Early detection and management of symptomatic gallstones is the key to prevent gallstones related complications. Total cholesterol content is highest in cholesterol stones. Total protein content is highest in pigment calculi and total iron is highest in pigment calculi. Chronic cholecystitis was the most common histopathological finding. There was no case of gallbladder carcinoma and there were no mortalities in the present study.

\section{KEY WORDS}

Gall stones, Laparoscopic Cholecystectomy, Cholelithiasis.

HOW TO CITE THIS ARTICLE: Byakodi KG, Vikram S, Hiregoudar A, et al. Study of clinical profile of cholelithiasis in KIMS, Hubli. J. Evolution Med. Dent. Sci. 2018;7(21):2604-2608, DOI: 10.14260/jemds/2018/586

'Financial or Other Competing Interest': None.

Submission 10-04-2018, Peer Review 05-05-2018,

Acceptance 11-05-2018, Published 21-05-2018.

Corresponding Author:

Dr. Byakodi K. G,

Department of General Surgery,

KIMS, Vidyanagar, Hubli-580021,

Karnataka, India.

E-mail: byakodi@gmail.com

DOI: $10.14260 /$ jemds $/ 2018 / 586$

\section{BACKGROUND}

Gallstone disease is one of the most common problems affecting the digestive tract. ${ }^{1}$ Autopsy reports have shown a prevalence of gallstones from 11 to $36 \% .^{2}$ The prevalence of gallstones is related to many factors including age, gender and ethnic background. ${ }^{3}$

Cholesterol cholelithiasis is one of the most prevalent and most costly digestive diseases in western countries. At least 20 million Americans (12\% of adults) have gallstones. The prevalence of gallstones appears to be rising and each year 
approximately one million new cases are discovered. ${ }^{4}$ In India it is estimated to be around $4 \%$, whereas in the western world it is about $10 \% .^{5}$ It is estimated that gallstone disease is 7 times more common in northern India than in the southern states. ${ }^{6}$ Although, many gallstones are silent, approximately one-third eventually cause symptoms and complications. The clinical spectrum of cholelithiasis ranges from an asymptomatic state to fatal complications.

Patients who have asymptomatic gallstones carry an annual risk of approximately $1 \%$ for biliary colic, of $0.3 \%$ for acute cholecystitis, of $0.2 \%$ for symptomatic choledocholithiasis and of $0.04 \%$ to $1.5 \%$ for gallstone pancreatitis (GSP).4,7 These small percentages, however, represent a large number of patients given overall. Although, advanced technologies have become more widely available, a clinically oriented approach remains paramount. Atypical as well as typical clinical symptoms should be recognised. Newer techniques of biliary imaging have simplified the diagnosis of bile duct stones. Non-invasive methods have the lowest risk, whereas invasive techniques have the greatest accuracy. ${ }^{8}$

The first cholecystectomy was performed in 1882 and it is now the most widely practiced mode of therapy for symptomatic gallstones. ${ }^{4}$ Especially, the advent of laparoscopic cholecystectomy is making a dramatic impact on the management of symptomatic patients with gallstones. An estimated 700,000 cholecystectomies are performed for gallstone disease each year. In addition, complications of gallstones result in 3000 deaths $(0.12 \%$ of all deaths) every year.

Studies on gallstone composition carried out in different parts of the world indicate a close link with dietary habits and ethnicity. ${ }^{9}$ This study describes an extensive quantitative analysis of gallstones in our patients including bacteriological and biochemical factors involved in formation of the same.

\section{MATERIALS AND METHODS}

This was a descriptive study conducted in Department of Surgery, KIMS, Hubli from April 2014 to Nov 2015. Totally, 56 patients were diagnosed to have symptomatic cholelithiasis with or without choledocholithiasis who underwent surgery were studied.

All the cases of either sex between 20 and 80 years admitted from April 2014 to Nov 2015 with clinically suspected gallstone disease in different surgical units were examined and investigated. Detailed history was taken and operated during the period. Information regarding the Age, Sex, Religion, Occupation, Socio-economic status, Nature of the symptoms, Past History of similar complaints, Diet history, Alcohol ingestion, Previous surgery; co-morbid conditions like Diabetes, Hypertension, Angina and Thyroid were obtained.

All patients underwent detailed investigations like Haemogram, ECG, LFT, Blood Sugar, Blood Urea, Serum Creatinine, Lipid profile, Urine analysis, Blood group, Chest $\mathrm{x}$ ray, Upper GI Endoscopy and Ultrasound scan of the abdomen with due importance to presence of stones in gallbladder, pericholecystic fluid collection, diameter of CBD, stones in CBD and associated pathology were recorded.

Relevant investigations like Bile Culture and Cytology and Biochemical Analysis of Gallstones and Speciality consultations were taken for patients with associated medical illness and their control was achieved. Risks and complications associated with surgery was explained to the patients and consent was taken. Pre-operative antibiotics were given. After opening the abdomen, the anatomical variations and pathological features were noted, bile obtained from the gallbladder and sent for culture sensitivity.

Based on clinical investigative parameters, the patients have undergone open or laparoscopic cholecystectomy and some of the patients have undergone CBD exploration with choledochoduodenostomy, choledochojejunostomy and primary repair of anatomical defect of umbilical hernia was done. A sub-hepatic tube drain was used in patients who underwent open cholecystectomy in selected cases.

The gallstones were sent for chemical analysis and the gallbladder for histopathological examination. All patients received antibiotics and routine post-operative care. Antibiotics were given and subsequently changed according to the bile culture and sensitivity report.

In patients who underwent open cholecystectomy, abdominal drain was removed on $3^{\text {rd }}-5^{\text {th }}$ post-operative day. Sutures were removed on $7^{\text {th }}-10^{\text {th }}$ post-operative day and were discharged on the $7^{\text {th }}-10^{\text {th }}$ day, unless any complications were present.

Patients were advised regarding diet, rest and to visit the surgical OPD for regular follow-up. In the follow-up period, attention was given to subject of improvement of the patient's condition with regard to symptomatic improvement as well as examination of the operative scar. In majority of cases long-term follow-up was not possible, as patients failed to turn up.

\section{Method of Gall Stone Analysis}

Gallstones from 56 patients with cholelithiasis were collected after cholecystectomy. The stones were divided into 3 groups depending upon their colour: pale yellow and whitish stones as cholesterol calculi, black and blackish brown as pigment calculi and brownish yellow or greenish with laminated features as mixed calculi. The various physical parameters of stones such as number, shape, size and texture were noted.

The stones were powdered in a pestle and mortar and dissolved in different solvents depending upon the type of chemical constituent to be analysed. To determine total cholesterol and total bilirubin, $30 \mathrm{mg}$ stone powder was dissolved in $3 \mathrm{~mL}$ chloroform in a test tube. The tube was kept in boiling water bath for 2 mins. The stone solution thus obtained was used for determination of total cholesterol and total bilirubin. To determine calcium, oxalate, inorganic phosphate, magnesium, chloride, soluble protein, triglycerides, iron, copper, sodium and potassium, $30 \mathrm{mg}$ stone powder was dissolved in $3 \mathrm{~mL}$ in HCL in graduated 10 $\mathrm{mL}$ tube and its final volume was made up to $10 \mathrm{~mL}$ with distilled water. The tube was kept in boiling water bath for 1 $\mathrm{hr}$. The dissolved stone solutions were stored at $2-8^{\circ} \mathrm{C}$ when not in use.

\section{Inclusion Criteria}

All patients of either sex between 20 and 80 years with Gallstone disease and who gave consent for the study.

\section{Exclusion Criteria}

- Patients below 20 years of age.

- Patients above 80 years of age.

- Malignancy of Gall Bladder that is Ca Gall Bladder.

- Patients who do not give consent for the study. 


\section{RESULTS}

This study includes a total of 56 cases who were studied prospectively over a period of 2 years and were treated on inpatient basis from April 2014 to Nov 2015.

\begin{tabular}{|c|c|c|}
\hline Age (yrs.) & No. of Patients & \% of Patients \\
\hline $20-29$ & 6 & 10.72 \\
\hline $30-39$ & 8 & 14.28 \\
\hline $40-49$ & 16 & 28.57 \\
\hline $50-59$ & 12 & 21.43 \\
\hline $60+$ & 14 & 25.00 \\
\hline Total & $\mathbf{5 6}$ & $\mathbf{1 0 0 . 0 0}$ \\
\hline \multicolumn{2}{|c|}{ Table 1. Distribution of Patients by Age Groups } \\
\hline
\end{tabular}

There is an increased incidence of cholelithiasis in the 5th and 6th decade with peak incidence in the 6th decade. In this study, the youngest patient was 21 years old and the oldest patient was 73 years old and average mean age was 48.37 .

\begin{tabular}{|c|c|c|}
\hline & No. of Patients & \% of Patients \\
\hline Male & 15 & 26.785 \\
\hline Female & 41 & 73.214 \\
\hline Total & $\mathbf{5 6}$ & $\mathbf{1 0 0 . 0 0 0}$ \\
\hline \multicolumn{2}{|r|}{ Table 2. Distribution of Patients by Sex } \\
\hline
\end{tabular}

In the present study, 41 patients were female, and 15 patients were male. The present study shows gallstones disease is a common problem in female population. The male to female ratio is $1: 2.7$.

\begin{tabular}{|c|c|c|}
\hline Symptoms & No. of Patients & \% of Patients \\
\hline Pain Abdomen & 53 & 94.64 \\
\hline Nausea and Vomiting & 15 & 26.78 \\
\hline Flatulent Dyspepsia & 02 & 3.57 \\
\hline Fever & 13 & 23.21 \\
\hline Jaundice & 04 & 7.14 \\
\hline Itching & 03 & 5.35 \\
\hline Pale Stools & 01 & 1.78 \\
\hline Urinary Symptoms & 02 & 3.57 \\
\hline \multicolumn{2}{|c|}{ Table 3. Distribution of Patients by Symptoms } \\
\hline
\end{tabular}

Pain was the commonest symptom presenting in 53 patients, 15 patients had nausea and vomiting, 02 had Flatulent Dyspepsia, 13 had Fever, 04 had Jaundice, 03 had Itching, 01 had Pale Stools and 02 had Urinary Symptoms. In present study, 37 patients had tenderness in the right hypochondrium and Epigastric pain, 03 patients had guarding. 01 patient had mass in the right hypochondrium, jaundice was present in 04 patients, distension was present in 1 patient, Murphy's sign was present in 02 patients and no signs in 08 patients. Also, in present study, 14 patients were vegetarian and 42 patients had mixed diet.

\begin{tabular}{|c|c|c|}
\hline Organisms & No. of Patients & \% of Patients \\
\hline Acinetobacter & 03 & 5.36 \\
\hline $\begin{array}{c}\text { Non-fermenting gram } \\
\text { negative bacilli }\end{array}$ & 06 & 10.72 \\
\hline Pseudomonas & 06 & 10.72 \\
\hline E-coli & 05 & 8.94 \\
\hline Providencia & 02 & 3.57 \\
\hline Klebsiella sp & 02 & 3.57 \\
\hline Proteus & 01 & 1.78 \\
\hline Citrobacter & 01 & 1.78 \\
\hline No growth & 22 & 39.28 \\
\hline
\end{tabular}

\begin{tabular}{|c|c|c|}
\hline $\begin{array}{l}\text { Conservatively managed } \\
\text { (Non-operated patients) }\end{array}$ & 08 & 14.28 \\
\hline Total & 56 & 100.00 \\
\hline
\end{tabular}

In this study bile culture showed No Growth (NG) in $39.28 \%$ of cases, in $14.28 \%$ no surgery was done, Nonfermenting gram negative bacilli in $10.72 \%$, Pseudomonas in $10.72 \%$, E-coli in $8.94 \%$, Acinetobacter in $5.36 \%$, Providencia and Klebsiella spp. in $3.57 \%$, Proteus and Citrobacter in $1.78 \%$ cases.

\begin{tabular}{|c|c|c|}
\hline Surgery & No. of Patients & \% of Patients \\
\hline Lap. Cholecystectomy & 30 & 53.58 \\
\hline $\begin{array}{c}\text { Lap. Cholecystectomy + ERCP } \\
\text { Sphincterotomy }\end{array}$ & 01 & 1.78 \\
\hline $\begin{array}{l}\text { Lap Cholecystectomy + } \\
\text { Umbilical Hernia Repair }\end{array}$ & 02 & 3.58 \\
\hline Open Cholecystectomy & 08 & 14.28 \\
\hline $\begin{array}{l}\text { Open Cholecystectomy + } \\
\text { Choledochoduodenostomy }\end{array}$ & 03 & 5.36 \\
\hline $\begin{array}{l}\text { Open Cholecystectomy+ } \\
\text { Choledochojejunostomy }\end{array}$ & 02 & 3.58 \\
\hline \begin{tabular}{|c|} 
Open Cholecystectomy+ CBD \\
Exploration
\end{tabular} & 01 & 1.78 \\
\hline $\begin{array}{c}\text { Exploratory Laparotomy for } \\
\text { Intestinal Obstruction } \\
\text { (Gallstone in Intestine) } \\
\end{array}$ & 01 & 1.78 \\
\hline $\begin{array}{l}\text { Conservatively Managed } \\
\text { (Non-Operated patients) }\end{array}$ & 08 & 14.28 \\
\hline Total & 56 & 100.00 \\
\hline
\end{tabular}

Out of 56 patients 48 patients underwent surgery, 08 were managed conservatively, Lap. cholecystectomy in 30, Lap. cholecystectomy + ERCP sphincterotomy in 01, Lap. cholecystectomy + hernia repair in 02 , Open cholecystectomy in 08 , Open cholecystectomy + choledochoduodenostomy in 03 , Open cholecystectomy + choledochojejunostomy in 02 , Open cholecystectomy + CBD exploration in 01 and Exploratory laparotomy for Intestinal Obstruction in 01 patient.

\begin{tabular}{|c|c|c|}
\hline Complications & No. of Patients & \% of Patients \\
\hline $\begin{array}{c}\text { Wound Infection } \\
\text { (WI) }\end{array}$ & 07 & 12.50 \\
\hline Bile Leak (BL) & 03 & 5.35 \\
\hline Fever & 32 & 57.14 \\
\hline Distension & 01 & 1.78 \\
\hline Stitch Abscess & 04 & 7.14 \\
\hline Fever + WI & 03 & 5.35 \\
\hline Fever + WI + BL & 03 & 5.35 \\
\hline $\begin{array}{c}\text { Conservatively } \\
\text { Managed } \\
\text { (Non-Operated } \\
\text { Patients) }\end{array}$ & 08 & 14.28 \\
\hline \multicolumn{2}{|c|}{ Table 6. Distribution of Patients by Complications } \\
\hline
\end{tabular}

In the present study 07 patients had wound infection, 03 patients had post-operative bile leak, 32 of them had fever, 04 patients had stitch abscess, 01 patient had abdominal distension and 08 patients had no surgery. Gallstones analysis was done, and 38 patients had multiple calculi, 16 patients had mixed type of stone, 04 patients had cholesterol stone and 18 patients had pigment stone. 


\section{DISCUSSION}

In this study, 56 cases of symptomatic cholelithiasis who were admitted at Karnataka Institute of Medical Sciences, Hubli between the period from April 2014 to Nov 2015 were studied. About 48 patients underwent surgery and 08 cases were managed conservatively. The observations of the study and results are compared with those of well-known authors. After a detailed history, clinical investigations and available treatment, following observations were noted.

In this study, patients were between 21 - 73 yrs. There is an increased incidence in the 5th and 6th decade with the maximum incidence in the 6 th decade. Similar incidence is seen in the studies of Pradhan SB et al ${ }^{10}$ (6th decade), Thamil et al11 (6th decade) and Mayank Devangan et al ${ }^{12}$ series showed peak incidence in 4 th to 5 th decade. Ezhilarasi et al 13 showed in 3rd to 4 th decade. The rise in the peak age of incidence is due to change in the dietary factors and lifestyle.

In the present study out of 58 cases, 41 were females and 15 were males. Thus forming M: F ratio of $1: 2.7$. Pradhan et al series showed $76.25 \%$ were females and $23.75 \%$ were males. Thamil et al series showed $61.5 \%$ were females and $38.46 \%$ were males. Arpit Bansal et al ${ }^{14}$ series showed $65 \%$ were females and $36 \%$ were males and Ezhilarasi et al showed $32 \%$ were males and $68 \%$ were females. Most of the studies showed female preponderance.

In present study pain was the commonest symptom presenting in 53 patients, 15 patients had Nausea and Vomiting, 02 had Flatulent Dyspepsia, 13 had Fever, 04 had Jaundice, 03 had Itching, 01 had Pale Stools and 02 had Urinary Symptoms.

Pain was the predominant symptom in the present study with $94.64 \%$. The commonest site of pain was in the Rt. hypochondrium and epigastric region and few patients had right lumbar pain. 20 patients had chronic recurring pain, 02 patients had acute onset of pain and pain was colicky in nature. Few had dull aching pain and radiation to back. Similar presentations were noted in the series of Pradhan et $\mathrm{al}^{10}(65 \%)$; Thamil et al (61.53\%), Mayank Devangan et al ${ }^{12}$ (96\%) and Arpit Bansal et al ${ }^{14}(100 \%)$ pain was the most common presentation.

15 patients $(26.78 \%$ of cases) in the present series had nausea/ vomiting. Vomiting was spontaneous, occurred mostly during the attack of pain. Vomiting in this study was similar to Pradhan et $\mathrm{al}^{10}$ series (50\%). In the present study, 04 patients $(7.14 \%)$ had jaundice. The cause of the jaundice was common bile duct calculi. The common bile ducts were explored in these patients and stones were removed. Out of 56 patients, 13 patients $(23.21 \%)$ had fever. Fever was secondary to cholangitis due to biliary obstruction. Fever was of moderate degree. All the patients were treated accordingly. Past history showed 20 patients had similar complaints in the past with on and off exacerbations.

42 patients $(75 \%)$ had mixed diet, 14 vegetarian diet (25\%) out of 56 patients. Similar findings were found in studies of Ezhil Arasi $\mathrm{N}$ et al ${ }^{13}$, Arpit Banasal et al ${ }^{14}$, Jayanthi et $\mathrm{al}^{15}$ and Pradhan et al ${ }^{10}$ series. Out of the 56 patients, 08 patients were obese. These observations are against the timehonoured aphorism that fat people are more prone for this disease. 06 patients were Diabetic, 03 patients were Asthmatic, 02 patients were Hypothyroid, 11 patients were Hypertensive, 01 patient had Immunodeficiency syndrome.
Tenderness in the Rt. Hypochondrium was present in $33(58.93 \%)$ patients and guarding was present in $02(3.57 \%)$ patients. A positive Murphy's sign present in 02 (3.57\%) patients. A mass was felt in $01(1.78 \%)$ patient. The mass could be due to distension of gallbladder or adherent omentum overlying the inflamed Gallbladder and Hepatomegaly.

All the patients have undergone routine haematological and biochemical investigations. The haemoglobin of patients ranged from 08 to $14 \mathrm{gm} \%$. Serum bilirubin was raised in 4 patients. Their bilirubin levels ranged from 1.02 to $22.2 \mathrm{mg} \%$.

Ultrasound scanning was done in all patients. All the cases revealed stones in the gall bladder and some in common bile duct. $44(78.57 \%)$ patients had stones in the gall bladder only, 04 (7.14\%) patients had stones in CBD, 05 (8.92\%) patients had stones in both gall bladder and common bile duct, $10(17.85 \%)$ patients had solitary stones in gall bladder, $34(60.71 \%)$ patients had multiple stones in gall bladder. Thickening of gall bladder was present in 11 (19.64\%) patients. Dilatation of the common bile duct was present in $08(14.28 \%)$ patients and associated findings were found in 14 (25.00\%) patients like (Fatty liver, Renal calculi, Hepatomegaly, IHBR dilatation, Umbilical hernia, Ascites, Ovarian Cyst, Absent left kidney). Many of the features in this study were similar to studies of Jayanthi et al ${ }^{15}$ and Arpit Bansal et al. ${ }^{14}$

A haemoglobin level of $10 \mathrm{gms} \%$ and above was accepted for the surgery. Blood transfusion was given to selected patients to improve the haemoglobin level. Cases diagnosed as acute cholecystitis were managed conservatively with IV fluids, nasogastric aspiration, antibiotics and analgesics. 8 patients were treated conservatively and were then offered interval cholecystectomy after 06 - 08 weeks. Diabetic patients were maintained on plain insulin injection in the pre-operative period. Associated medical illness was treated accordingly before taking the patient to surgery.

In the present study 48 patients underwent surgery, 08 were managed conservatively. 30 patients underwent Laparoscopic cholecystectomy and 02 patients underwent Open cholecystectomy. Lap. cholecystectomy was done in 30, Lap. cholecystectomy + ERCP sphincterotomy in 01, Lap. cholecystectomy + hernia repair in 02 , Open cholecystectomy in 08 , Open cholecystectomy + choledochoduodenostomy in 03 , Open cholecystectomy + choledochojejunostomy in 02 , Open cholecystectomy + CBD exploration in 01, Exploratory laparotomy in 01 patient. The most common incision used in open cholecystectomy was right sub-costal incision. Open cholecystectomy + CBD Exploration and T-tube drainage was done in 01 patient $(1.78 \%), 01$ patient underwent Exploratory laparotomy for gallstone ileus secondary to faecolith. All the patients were given IV fluids. Nasogastric aspiration was done in selective patients and antibiotics and analgesics were given. Drainage tube was removed between 3 to 10 days based upon the drainage. T-Tube cholangiogram was performed in 1 patient and T-Tube was removed after confirmation of the patency of the duct after 14 days.

In the present study fever was the most common adverse symptom (57.14\%), wound infection in $12.50 \%$, Bile leak (5.35\%), Stitch abscess (7.14\%) and Abdominal distension $(1.78 \%)$ were other complications. In this case, drain was removed on the 7 th - 8th day. 
There was no mortality, no pulmonary complications, no iatrogenic injury to CBD reported in this study. The average post-operative stay in hospital for Lap. cholecystectomy was 4.44 days, Open cholecystectomy was 5.87 days, Open cholecystectomy with CBD exploration was 27.00 days, Open cholecystectomy with choledochojejunostomy and choledochoduodenostomy was 13.50 days. The average duration of stay can be reduced in post-operative group by adequate use of prophylactic antibiotics and good nursing care.

In the present study 20 patients were reported as having chronic cholecystitis, 02 patients had acute cholecystitis with cholelithiasis, 19 patients were reported to have Chronic cholecystitis with cholelithiasis, 05 patients were reported to have Calculus cholecystitis, 01 patient was reported to have Gallstones in intestine. No case of malignancy was noted in the study. Similar findings were noted in R. Thamil et al and Maulik $\mathrm{K}$ et $\mathrm{al}^{16}$ series, thus signifying that most common histopathological changes seen in gall bladder secondary to gall stones is chronic cholecystitis.

In the present study $42.10 \%$ had mixed stones and $10.52 \%$ had cholesterol stones, $47.36 \%$ had pigmented stones which is similar to the studies of Arpit Bansal et al,14 Ezhil Arasi et al,13 R Thamil et al and Pradhan et al. ${ }^{10}$ Bile culture was done in all patients, 22 patients had no growth, 06 had non-fermenting gram negative bacilli, 06 cases had Pseudomonas, 05 cases reported growth of E. coli, 02 patients had growth of Klebsiella, 01 patient reported the growth of Citrobacter.

Regular follow-up of patients was done. There was no problem in the follow-up period in any patient. Conservatively managed patients had not reported for interval surgery, because of limited period of follow-up of patients nothing can be commented over the patients.

The Gallstones were divided into 3 groups depending upon their colour: pale yellow and whitish stones as cholesterol calculi, black and blackish brown as pigment calculi and brownish yellow or greenish with laminated features as mixed calculi. The cholesterol, bilirubin, triglycerides, soluble protein, calcium, magnesium, copper, iron, inorganic phosphate and chloride were found in all gallstones.

\section{CONCLUSION}

Gallstone disease is more common in female patients. The incidence of gallstones was higher in the 5th and 6th decades of life. Gall stones incidence is more in non-vegetarians than vegetarians. The commonest symptom was pain abdomen. Ultrasonography was the investigation of choice and helps in early screening and detection of gallstones.

The commonest type of the stone was pigment stone. Bile culture revealed no growth in majority cases. Laparoscopic cholecystectomy is better than any other procedure for cholecystectomy. Among post-op complications, wound infection and other complications are more predominant in open cholecystectomy. Early cholecystectomy is the treatment of choice in symptomatic patients.

Total cholesterol content is highest in cholesterol stones. Total protein content is highest in pigment calculi and Total iron is highest in pigment calculi. Chronic cholecystitis was the most common histopathological finding. There was no case of gallbladder carcinoma and there were no mortalities in the present study.

\section{REFERENCES}

[1] Brunicardi FC, Margrett, Thai H. Gall Bladder and the extrahepatic biliary system. Schwartz principles of surgery. $8^{\text {th }}$ edn. 2009: p. 1135-67.

[2] Tandon RK. Prevalence and type of biliary stones in India. World J Gastroenterol 2000;6(Suppl 3):4-5.

[3] Yeo CJ, Matthews JB, McFadden DW, et al. Shackelford's Surgery of the alimentary tract. $7^{\text {th }}$ edn. China: Elsevier Saunders 2013: p. 1291.

[4] Hardy KJ. Carl Langenbuch and the Lazarus hospital: events and circumstances surrounding the first cholecystectomy. Aust N Z J Surg 1993;63(1):56-64.

[5] Feldman M, Friedman LS, Brandt LJ. Sleisenger and Fordtran's Gastrointestinal and liver disease: pathophysiology/diagnosis/management. $9^{\text {th }}$ edn. Canada: Saunders Elsevier 2010: p. 779.

[6] Brunicardi FC, Andersen DK, Billiar TR, et al. Schwartz's Principles of surgery. 10 $0^{\text {th }}$ edn. New York: McGraw-Hill Education 2014: p. 1038.

[7] Brunicardi FC, Andersen DK, Billiar TR, et al. Schwartz's Principles of surgery. $10^{\text {th }}$ edn. New York: McGraw-Hill Education 2014: p. 1317-8.

[8] Wang DQH, Afdhal NH. Gallstone disease. Chap - 65. In: Feldman M, Friedman LS, Brandt LJ, eds. Sleisenger Fordtran's Gastrointestinal liver disease. 9th edn Philadelphia, Pa: Saunders Elsevier 2010: p. 1089-111.

[9] Townsend Jr CM, Beauchamp RD, Evers BM, et al. Sabiston textbook of surgery: the biological basis of modern surgical practice. 19th edn. Philadelphia: Elsevier Saunders 2012: p. 1182.

[10] Pradhan SB, Joshi MR, Vaidya A. Prevalence of different types of gallstone in the patients with cholelithiasis at Kathmandu Medical College, Nepal. Kathmandu University Medical Journal 2009;7(27):268-71.

[11] ThamilSelvi R, Sinha P, Subramaniam PM, et al. A clinicopathological study of cholecystitis with special reference to analysis of cholelithiasis. International Journal of Basic Medical Science 2011;2(2):68-72.

[12] Devangan M, Siddharth RK, Ramteke S. A study on bacteriological profile of bile and gallstone on adult patient of cholelithiasis. Indian Journal of Applied Research 2015;5(10):29-33.

[13] EzhilArasi N, Aruna L, Bushra AB, et al. Clinicopathological study of chronic calculous cholecystitis with chemical analysis of gallstones. International Journal of Research in Health Science 2015;3(4):435-41.

[14] Bansal A, Akhtar M, Bansal AK. A clinical study: prevalence and management of cholelithiasis. International Surgery Journal 2014;1(3):134-9.

[15] Jayanthi V, Anand L, Ashok L, et al. Dietary factors in pathogenesis of gallstone disease in southern India- a hospital-based case-control study. Indian J Gastroenterology 2005;24(3):97-9.

[16] Maulik K, Mehariya, Patel MB, et al. Histopathological study of gall Bladder. International J Res Med 2014;3(4):96-9. 